\title{
RESISTENCIA PARCIAL Y ESPECÍFICA A ROYA DEL TALLO EN LA LINEA AVANZADA DE TRIGO HARINERO 'KIJIL'
}

\author{
PARTIAL AND SPECIFIC RESISTANCE TO STEM RUST \\ IN THE ADVANCED BREAD WHEAT LINE 'KIJIL'
}

\section{Maricarmen Sandoval-Sánchez ${ }^{1}$, Julio Huerta-Espino², Ravi P. Singh ${ }^{3}$, Mandeep Singh-Randhawa ${ }^{4}$, Reyna I. Rojas-Martínez ${ }^{1 *}$, Ignacio Benitez-Riquelme ${ }^{5}$ y Cristian Nava-Díaz ${ }^{1}$}

\begin{abstract}
'Colegio de Postgraduados (COLPOS), Fitopatología, Campus Montecillo, Texcoco, Edo. de México, México. ${ }^{2}$ Instituto Nacional de Investigaciones Forestales, Agrícolas y Pecuarias, Campo Experimental Valle de México, Texcoco, Estado de México, México. ${ }^{3}$ Centro Internacional de Mejoramiento de Maíz y Trigo (CIMMYT), Texcoco, Estado de México, México. ${ }^{4}$ CIMMYT, ICRAF House, Nairobi, Kenya. ${ }^{5}$ COLPOS, Recursos Genéticos y Productividad, Campus Montecillo, Texcoco, Estado de México, México.
\end{abstract}

*Autor de correspondencia (rojas@colpos.mx)

\section{RESUMEN}

El hongo Puccina graminis f. sp. tritici es el agente causal de la roya del tallo del trigo (Triticum aestivum), éste puede causar pérdidas del rendimiento hasta de $40 \%$ en variedades susceptibles, además puede mutar y vencer genes de resistencia, por lo que es necesario identificar nuevas fuentes de resistencia para combatir las razas virulentas de este patógeno. La línea avanzada de trigo harinero Kijil ha mostrado niveles altos de resistencia a roya del tallo en las etapas de plántula y planta adulta pero se desconoce el número de genes que confieren tal resistencia. Se investigó la genética de la resistencia a roya del tallo en una población $\mathrm{F}_{6}$ conformada por 99 familias derivadas de la cruza Apav \#1 $\times$ Kijil. Los ensayos en invernadero y en campo se llevaron a cabo en El Batán, Texcoco y en Ciudad Obregón, Sonora, México, respectivamente, durante 2016 y 2017. El análisis genético indicó que existen cuatro genes de raza específica que confieren resistencia en etapa de plántula. El primer gen se identificó como $\mathrm{Sr} 38$ y los otros tres se designaron temporalmente como SrKj;1, SrKj22+ y SrKjX-, de acuerdo con los tipos de infección registrados. En etapa de planta adulta, las familias positivas a Sr38 presentaron niveles de severidad de 0 a $20 \%$, mientras que las familias portadoras de SrKj; 1, SrKj22+ y SrKjX- presentaron severidades de 1 a $30 \%$, de 30 a $60 \%$ y de 1 a $30 \%$, respectivamente. Adicionalmente, se determinó que existen tres genes que confieren resistencia sólo en etapa de planta adulta, entre ellos Sr2 y Sr58. Las familias positivas a Sr58 mostraron severidades de 30 a $90 \%$ y sólo una familia presentó $5 \%$; aquellas familias positivas a Sr2 + Sr58 presentaron de 60 a $100 \%$ de severidad. De acuerdo con los resultados, Kijil es una fuente potencial de resistencia a roya del tallo por conferir altos niveles de resistencia en etapas de plántula y planta adulta.

Palabras clave: Triticum aestivum, Puccina graminis f. sp. tritici, resistencia de raza específica, resistencia de raza no específica.

\section{SUMMARY}

The fungus Puccina graminis $\mathrm{f}$. sp. tritici is the causal agent of wheat (Triticum aestivum) stem rust, it can cause yield losses of up to $40 \%$ in susceptible varieties; it can also mutate and overcome resistance genes, so it is necessary to identify new sources of resistance to fight the virulent races of this pathogen. Bread wheat advanced line Kijil has shown high levels of resistance to stem rust in the stages of seedling and adult plant, but the number of genes that confer such resistance is unknown. The genetics of stem rust resistance was investigated in an $\mathrm{F}_{6}$ population consisting of 99 families derived from the Apav \#1 $\times$ Kijil cross. Greenhouse and field trials were carried out in El Batán, Texcoco and Ciudad Obregón, Sonora, Mexico, respectively, during 2016 and 2017. Genetic analysis indicated that there are four race-specific genes that confer resistance in seedling stage. The first gene was identified as $\mathrm{Sr} 38$ and the other three were temporarily designated as SrKj; 1, SrKj22+ and SrKjX-, according to the infection types recorded. In adult plant stage, the families positive to $S r 38$, showed severities of 0 to $20 \%$, while families carrying SrKj; 1, SrKj22+ and SrKjX- genes presented severities from 1 to $30 \%, 30$ to $60 \%$ and 1 to $30 \%$, respectively. Additionally, it was determined that there are three genes that confer resistance only in adult plant stage, including $\mathrm{Sr} 2$ and $\mathrm{Sr} 58$. Families positive to Sr58 displayed severities from 30 to $90 \%$ and only one family presented $5 \%$; those families positive to Sr2 + Sr58 presented 60 to $100 \%$ severity. According to the results, Kijil is a potential source of resistance to stem rust by conferring high levels of resistance in seedling and adult plant stages.

Index words: Triticum aestivum, Puccina graminis f. sp. tritici, racespecific resistance, non-specific race resistance.

\section{INTRODUCCIÓN}

La roya del tallo, causada por el hongo Puccina graminis f. sp. tritici Erikss. \& Hennin, es una enfermedad importante del trigo harinero (Triticum aestivum L.) y representa una amenaza potencial en la mayoría de las regiones productoras de este cereal alrededor del mundo (Randhawa et al., 2018b). En variedades susceptibles, la enfermedad puede causar pérdidas del rendimiento de 40 \% en países como India, Pakistán, Bangladesh, China, Kenia, Etiopía y Brasil (Dubin y Brennan, 2009). La roya del tallo se ha controlado principalmente a través de la incorporación de resistencia al germoplasma de trigo y mediante la erradicación del hospedante alterno (Berberis spp.) de P. graminis f. sp. tritici (Huerta-Espino et al., 2011; Singh et al., 2011a).

En México, la incidencia de roya del tallo ha disminuido considerablemente y sólo se encuentra en niveles significativamente bajos desde que se liberó la variedad Yaqui 50 y otras variedades portadoras del gen Sr2, entre otros; además, no se han observado cambios en las razas 
de roya del tallo en México en los últimos 40 años y las infecciones naturales son prácticamente inexistentes (Huerta-Espino et al., 2011; Singh et al., 2006); sin embargo, la raza TTKSK (Ug99) que ha causado daños severos, principalmente en el continente africano, representa una amenaza potencial en México (García-León et al., 2018).

Se han identificado 59 genes de resistencia para roya del tallo (Mclntosh et al., 2017), la mayoría de los cuales son de raza específica y confieren un efecto mayor en la resistencia desde la etapa de plántula hasta la etapa de planta adulta; sin embargo, este tipo de resistencia es poco durable ya que el patógeno puede evolucionar hacia virulencia y vencer estos genes de resistencia que generalmente se usan individualmente. Por otra parte, los genes de raza no específica confieren resistencia en planta adulta y sus efectos individuales son menores, pero cuando se conjuntan tres o más suman sus efectos y se heredan como una característica cuantitativa (Johnson, 1981).

La resistencia parcial, o de infección lenta (Niederhauser et al., 1954), también se conoce como resistencia de raza no específica y generalmente es asociada con la resistencia durable y referida comúnmente como resistencia de planta adulta porque se expresa como un desarrollo lento de la enfermedad en el campo, comparativamente con un testigo susceptible (Herrera-Foessel et al., 2014). La acumulación de genes que confieren resistencia parcial explota los efectos aditivos de este tipo de genes (ZárateCastrejón et al., 2018). Diversos estudios han revelado que las combinaciones de tres a cinco genes de resistencia resultan en niveles de infección cercana a la inmunidad y en resistencia estable a través de diferentes ambientes (Rodríguez-García et al., 2019; Singh et al., 2000; Singh et al., 2011b); así mismo, se pueden lograr niveles altos de resistencia a royas cuando un gen de raza específica efectivo se combina con genes de planta adulta (Basnet et al., 2015).

Se han catalogado y designado pocos genes de planta adulta con efectos individuales menores. Los conocidos como Sr2/Lr27/Yr30/Pbc7, Sr57/Lr34/Yr18/Pm38/Stb1/ Ltn1, Sr58/Lr46/Yr29/ Pm39/Ltn2 y Sr55/Lr67/Yr46/ Pm46 muestran un efecto pleiotrópico; es decir, confieren resistencia a múltiples enfermedades como roya del tallo, roya de la hoja (Puccinia triticina Erikss.), roya amarilla (P. striiformis f. sp. tritici Westend) y cenicilla polvorienta (Blumeria graminis (DC) Speer f. sp. tritici emend. É. J. Marchal) (Herrera-Foessel et al., 2014).

Se han transferido al trigo harinero diversos genes de resistencia a roya del tallo provenientes de ancestros silvestres, tales como Sr27, Sr22 y Sr35, a partir de Triticum monococcum (Kerber and Dyck, 1973; Mclntosh et al., 1984; The, 1973); Sr24, Sr25, Sr26 y Sr43 a partir de Thinopyrum ponticum (Mclntosh et al., 1977; Niu et al., 2014) o Sr38 proveniente de T. ventricosum (Bariana and Mclntosh, 1993).

La resistencia genética a royas es el método más seguro y amigable ambientalmente para reducir las pérdidas de rendimiento, comparado con el control químico. Debido a que las razas virulentas de la roya del tallo continúan representando una amenaza seria en la producción mundial de trigo, es necesario y con propósitos de prevención, identificar y caracterizar nuevos genes de resistencia. En este sentido, la línea avanzada de trigo harinero Kijil (KLEIN DON ENRIQUE*2/3/FRET2/WBLL1//TACUPETO F2001), desarrollada por el programa de mejoramiento genético de trigos harineros del Centro Internacional de Mejoramiento de Maíz y Trigo (CIMMYT), ha mostrado niveles altos de resistencia a roya del tallo en plántula y planta adulta. El objetivo de esta investigación fue determinar el número de genes de plántula y planta adulta que están confiriendo la resistencia a roya del tallo en la población $F_{6}$ de la cruza Apav \#1 × Kijil.

\section{MATERIALES Y MÉTODOS}

\section{Material vegetal}

Se utilizó una población $\mathrm{F}_{6}$ conformada por 99 familias derivadas de la cruza Apav \#1 × Kijil. Apav \#1 es una línea altamente susceptible a la roya del tallo, derivada de la cruza Avocet S × Pavon 76 (Randhawa et al., 2018a). Kijil proviene de la cruza KLEIN DON ENRIQUE*2/3/FRET2/ WBLL1//TACUPETO F2001 y en el presente estudio mostró niveles altos de resistencia a la raza RTR de roya del tallo (la más común en México) en plántula en el invernadero y en planta adulta en campo. La población se desarrolló mediante una cruza simple y la $F_{2}$ se obtuvo del grano cosechado proveniente de tres plantas $F_{1}$. Las poblaciones $F_{2}$ de cada planta $F_{1}$ fueron evaluadas fenotípicamente, dos de éstas fueron correctas y se eliminó la progenie de la tercera planta. De las dos poblaciones $F_{2}$ restantes se cosechó al azar un número suficientemente grande de espigas que se trillaron en masa para avanzar a la siguiente generación. En la generación $F_{4}$ se generaron líneas puras a partir de la cosecha individual de 200 espigas, las cuales se sembraron en espiga por surco para obtener la $F_{5}$. La progenie de las 200 espigas por surco se cosechó en masa para dar origen a la generación $F_{6}$. En todas las generaciones se aplicó fungicida para evitar la pérdida de plantas susceptibles. 


\section{Evaluación de las familias en plántula}

Las 99 familias de Apav \#1 $\times$ Kijil y los progenitores se evaluaron en etapa de plántula en el invernadero de royas del Centro Internacional de Mejoramiento de Maíz y Trigo durante el mes de junio de 2017. Se sembraron ocho semillas por familia en charolas de plástico $(20 \times 30$ $\times 6 \mathrm{~cm})$ a las cuales se les agregó una mezcla de tierra preparada y peat moss $(60 / 40 \mathrm{v} / \mathrm{v})$ y con una plancha de acero se formaron 24 orificios por charola sobre el sustrato; adicionalmente, se sembró un juego con 20 líneas diferenciales del Laboratorio de Enfermedades de Cereales (CDL) de Minnesota, EUA (Jin et al., 2007). Las charolas se acomodaron en un diseño de bloques completos al azar y se mantuvieron en el invernadero con temperaturas de 20 a $25^{\circ} \mathrm{C}$. Las plántulas se inocularon 10 días después de la siembra (dds), cuando las plántulas desarrollaron la segunda hoja, a través de aspersiones de urediniosporas de la raza RTR suspendidas en aceite mineral Soltrol 170® (Chevron Phillips Chemical Company) a una concentración de $1 \times 10^{-6}$ esporas $\mathrm{mL}^{-1}$. La fórmula de avirulencia/ virulencia de RTR es: Sr7a, 9e, 10, 12, 13, 14, 22, 23, 24, 25, 26, 27, 29, 30, 37, 32, 33, 35, Dp2, H, Gt, Wld, W3560, Agl / Sr5, 6, 7b, 8a, 8b, 9a, 9b, 9d, 9f, 9g, 17, 15, 17, 21, 28, 34, 36, PI (Singh, 1991). Las plántulas se colocaron dentro de una cámara de rocío durante $9 \mathrm{~h}$ y $3 \mathrm{~h}$ de luz a $20^{\circ} \mathrm{C}$ y después de $16 \mathrm{~h}$ se trasladaron al invernadero en donde se mantuvieron a $24{ }^{\circ} \mathrm{C}$ durante el día y $12{ }^{\circ} \mathrm{C}$ durante la noche.

Los tipos de infección en las familias y los progenitores se registraron 14 días después de la inoculación (ddi) mediante la escala de 0 a 4 de Roelfs et al. (1992), donde las plantas con tipos de infección 0, ; (fleck), 1, 2 y X se consideran resistentes, mientras que los tipos de infección 3 y 4 se utilizan para designar plantas susceptibles. Los signos $+y$ - describen si el tamaño de la uredinia es más grande o más pequeño, respectivamente, comparado con el tamaño normal.

\section{Evaluación de las familias en planta adulta}

Las familias $\mathrm{F}_{6}$ y los progenitores resistente y susceptible (Apav y Kijil) se evaluaron por su resistencia en planta adulta en un ensayo en bloques completamente al azar con una sola repetición en la estación experimental del CIMMYT en Ciudad Obregón, Sonora durante los ciclos 2015-2016 y 2016-2017. En campo, cada familia $F_{6}$ se sembró en parcelas que incluyeron aproximadamente 70 plantas dispuestas en dos filas paralelas de $1 \mathrm{~m}$. Los bloques fueron constituidos por 25 familias. A un lado de cada parcela y alrededor del lote experimental se sembró una mezcla de genotipos susceptibles a la raza RTR de roya del tallo, que sirvieron como fuente de inóculo.
Para hacer una eficiente evaluación y clasificación de las familias $F_{6}$ por su reacción a la roya del tallo fue necesario crear epidemias artificiales mediante tres inoculaciones, por medio de una suspensión de urediniosporas de la raza RTR (Singh, 1991). Las urediniosporas fueron suspendidas en aceite mineral Soltrol@ 170 (Chevron Phillips Chemical Company) y asperjadas con un atomizador manual La severidad de la enfermedad se registró cuando el progenitor susceptible (Apav) alcanzó niveles de 80 a $100 \%$; se utilizó la escala de Cobb modificada (Peterson et al., 1948) y la respuesta del hospedante a la infección se determinó de acuerdo con Roelfs et al. (1992), donde: $\mathrm{R}=$ resistente, uredinias diminutas; $\mathrm{MR}=$ resistencia moderada, uredinias pequeñas; $M S$ = susceptibilidad moderada, uredinias pequeñas de tamaño moderado y $S$ = susceptible, uredinias grandes.

\section{Clasificación de familias}

Con base en la severidad de la enfermedad y la respuesta a la infección, las familias $F_{6}$ fueron clasificadas en tres categorías fenotípicas, de acuerdo con Singh y Rajaram (1992): líneas homocigotas parentales tipo resistentes (LHPTR), líneas homocigotas parentales tipo susceptible (LHPTS) y líneas con respuesta diferente a los dos padres (OTROS).

\section{Análisis genético}

Los experimentos en campo se llevaron a cabo con una sola repetición, es decir; una serie sencilla; la estimación del número de genes se realizó mediante el análisis de segregación mendeliana tradicional y las frecuencias fenotípicas observadas se compararon con las frecuencias fenotípicas esperadas mediante la prueba de ji-cuadrada $\left(X^{2}\right)$ (Singh y Rajaram, 1992); técnica utilizada en otros trabajos de investigación de la misma naturaleza (Huerta et al., 2012; Ponce-Molina et al., 2018).

\section{Análisis molecular}

El ADN de los progenitores y las familias se extrajo de tejido foliar de aproximadamente 20 plantas por familia sembradas en invernadero a través del método CTAB (bromuro de cetiltrimetilamonio) (Dreisigacker et al., 2016). Los progenitores se analizaron con cinco marcadores moleculares ligados a genes de resistencia de planta adulta: 1) marcador de repeticiones de secuencia simple (SSR) Xgwm533 ligado al gen Sr2 (Spielmeyer et al., 2003); 2) marcador de secuencia polimórfica amplificada y cortada (CAPS) csLV46G22 ligado al gen Sr58 (Lagudah, Com. Pers.) '; 3 y 4) marcador de secuencia de sitio

'E. S. Lagudah. CSIRO Plant Industry, Canberra, Australia. 
marcado (STS) csLV34 (Lagudah et al., 2006) y marcador de polimorfismo de nucleótido único (SNP) Lr34SNP, respectivamente (Lagudah et al., 2009), ligados al gen Sr57; y 5) Lr67SNP-TM4 ligado al gen Sr55 (Moore et al., 2015). Adicionalmente, los progenitores se analizaron con el marcador CAPS VENTRIUP-LN2 ligado al gen de raza específica Sr38 (Helguera et al., 2003). Los marcadores Xgwm533, cSLV46G22 y VENTRIUP-LN2 resultaron polimórficos entre los progenitores, por lo que se usaron para genotipar toda la población con el uso de los protocolos de PCR de Helguera et al. (2003) y Dreisigacker et al. (2016).

\section{RESULTADOS}

\section{Análisis genético y molecular en plántula}

El progenitor susceptible Apav \#1 mostró el tipo de infección 3+ mientras que el progenitor resistente Kijil mostró el tipo de infección; (fleck). El análisis de segregación mendeliana indicó que al clasificar las familias en resistentes y susceptibles, la resistencia en Kijil está condicionada por cuatro genes de raza específica (Cuadro 1). Con base en el análisis molecular, uno de los cuatro genes de raza específica se identificó como Sr38, ya que Kijil resultó positivo para el marcador VENTRIUP-LN2. Para observar la segregación del gen Sr38 en las 99 familias éstas se analizaron con el marcador VENTRIUP-LN2. Un total de 37 familias resultaron positivas al marcador VENTRIUP-LN2, de las cuales, 32 se agruparon como resistentes y cinco como susceptibles (Cuadro 1). Las 32 familias resistentes expresaron los tipos de infección ; 0 ; $; 1-, ; 1,2,22+$ y X, lo cual indica que los tipos de infección son consistentes con los resultados del marcador.

Las 62 familias negativas al marcador VENTRIUPLN2 se agruparon en 44 resistentes y 18 susceptibles de acuerdo con el tipo de infección. Las resistentes mostraron los tipos de infección ; $1, ; 1-, ;$, 2, 22+y X-y las susceptibles $3+$ y 33+. Con base en el análisis de segregación de las 62 familias, se dedujo que existen dos genes que confieren resistencia a roya del tallo en plántula (Cuadro 1).
Al reclasificar las 44 familias resistentes y negativas a VENTRIUP-LN2, se observó que existen familias que agrupan tres tipos consistentes de infección: 25 familias registraron ; 1, 12 presentaron 22+y $7 X$-. De acuerdo con los tipos de infección, los genes se designaron temporalmente como SrKj; 1, SrKj22+ y SrKjX-, los cuales corresponden al segundo, tercero y cuarto gen que confieren resistencia a roya del tallo en plántula. El análisis molecular no identificó a dichos genes.

\section{Efecto de los genes Sr38, SrKj;1, SrKj22+ y SrKjX- en planta adulta}

Para corroborar el efecto del gen Sr38 en planta adulta en las 32 familias agrupadas como resistentes en plántula, se mostró que 22 presentaron un nivel de infección en planta adulta de 0 a $1 \%(R)$, muy similar a Kijil (1\% R), mientras que las 10 restantes presentaron severidades en un intervalo de 5 a $20 \%$ (R-MR). Las familias portadoras de los genes SrKj;1, SrKj22+ y SrKjX-presentaron intervalos de severidad de 1 a $30 \%$ (R-MR), de 30 a $60 \%$ (MR) y de 1 a $30 \%(\mathrm{R}-\mathrm{MR})$, respectivamente.

\section{Análisis genético y molecular en planta adulta}

De las 99 familias, se identificaron 23 que resultaron susceptibles en plántula, las cuales se utilizaron para realizar el análisis genético. La severidad final de roya del tallo en Kijil fue 1 \% (R) y 100 \% (S) para Apav \# 1. El análisis genético indicó que la resistencia a roya del tallo en la población proveniente de Apav \#1 $\times$ Kijil está conferida por tres genes de resistencia de planta adulta (Cuadro 2). De las 23 familias, 21 fueron positivas al marcador csLV46G22, ligado a Sr58, y mostraron severidades de 30 a $90 \%$ (MS-S); una de esas familias presentó $5 \%$ (MS) de infección. Sólo 10 familias resultaron positivas a los marcadores de $\mathrm{Sr} 2+\mathrm{Sr} 58$ y el intervalo de severidad fue de 60 a $100 \%$ (MS-S). Las dos familias restantes fueron negativas a ambos marcadores y presentaron severidades de 90 y $100 \%(S)$.

Cuadro 1. Número de genes de resistencia de plántula a roya del tallo en la población de 99 familias $\mathrm{F}_{6}$ de Apav \#1 $\times$ Kijil, estimado a través del análisis de segregación mendeliana durante el ciclo 2016-2017 en Ciudad Obregón, Sonora.

\begin{tabular}{|c|c|c|c|c|c|}
\hline & \multicolumn{3}{|c|}{ Número de familias } & \multirow{2}{*}{$x^{2}$} & \multirow{2}{*}{ No. de genes } \\
\hline & Total & Resistentes & Susceptibles & & \\
\hline Familias $F_{6}$ & 99 & 76 & 23 & 0.01 & 2 \\
\hline Positivas a VENTRIUP-LN2 & 37 & 32 & $5^{+}$ & - & - \\
\hline Negativas a VENTRIUP-LN2 & 62 & 44 & 18 & 0.05 & 2 \\
\hline
\end{tabular}

${ }^{\dagger}$ Falsos positivos. 
Cuadro 2. Número de genes de resistencia de planta adulta (APR) a roya del tallo en la población $\mathrm{F}_{6}$ Apav\# $1 \times$ Kijil, estimado a través del análisis de segregación mendeliana en Ciudad Obregón, Sonora, ciclo 2016-2017.

\begin{tabular}{|c|c|c|c|c|}
\hline & \multicolumn{2}{|c|}{ Número de familias } & $x^{2}$ & No. de genes \\
\hline Total & Resistentes & Susceptibles & & \\
\hline 23 & 20 & 3 & 0.26 & 3 \\
\hline
\end{tabular}

La distribución de frecuencias de las familias para severidad de roya del tallo resultó de tipo discreta con tendencia a la resistencia, lo cual puede explicarse por la presencia de los genes de raza específica que confieren un nivel alto de protección en la etapa adulta de la planta (Figura 1).

En el Cuadro 3 se muestra el número de familias positivas y negativas a los marcadores ligados a los genes Sr2, Sr38 y Sr58. No fue posible cuantificar el efecto individual de cada uno de esos genes en planta adulta, ya que las familias portadoras de esos genes también portan otros genes de raza específica.

\section{DISCUSIÓN}

El análisis de segregación mendeliana indicó que la resistencia a la roya del tallo en la población derivada de Apav \#1 × Kijil en plántula está determinada por cuatro genes de raza específica. De acuerdo con el marcador molecular VENTRIUP-LN2, un primer gen se identificó como Sr38 y los otros tres se denominaron temporalmente SrKj; 7, SrKj22+ y SrKjX-. El segmento del cromosoma 2NS/2AS que contiene los genes de resistencia Sr38/Yr17/
Lr37 fue incorporado al trigo harinero VPM1 a partir de T. ventricosum (Tausch) Cess. Estos genes de raza específica confieren resistencia a roya del tallo (Sr38), roya amarilla (Yr17) y roya de la hoja (Lr37) (Bariana y McIntosh, 1993; Helguera et al., 2003) y han sido una fuente de resistencia ampliamente utilizada en los programas de mejoramiento. Actualmente, el gen Sr38 no provee resistencia contra el grupo de razas TTKSK (Ug99), pero es efectivo contra otras razas presentes en Norteamérica, especialmente en la etapa de planta adulta (Zhang et al., 2014).

En el presente estudio, la evaluación fenotípica en plántula indicó que las familias resistentes y positivas a Sr38 expresaron los tipos de infección ; $0 ;, ; 1-, ; 1,2,22+y$ X, mientras que aquellas susceptibles y positivas al marcador mostraron los tipos de infección 3+ y 33+ C, lo que indica falsos positivos para el marcador. Los resultados aquí obtenidos se encuentran dentro de los tipos de infección reportados para Sr38: X con pústulas más grandes hacia la base de la hoja (McIntosh et al., 1995), ; 2, 3 (Jin et al., 2007), $\mathrm{X}+\mathrm{y} 3+$ (Singh et al., 2008), $0 ;, ;, ; 1, ; 13-, ; 13, ; 3,3$; (Zhang et al., 2014) y 0; a ;13-C (Turner et al., 2016). Zhang et al. (2014) reportaron que Sr38 fue el gen más frecuente en los trigos duros y harineros que evaluaron; así mismo, mencionaron

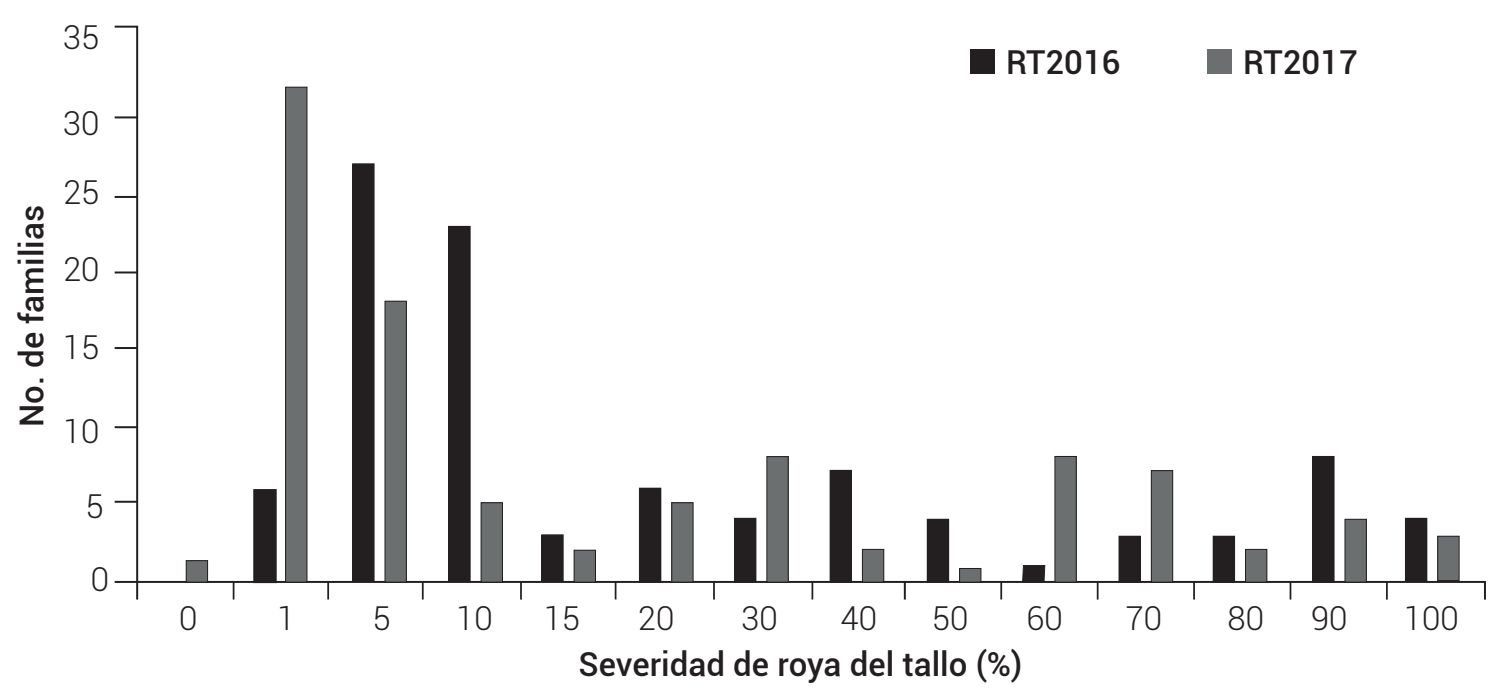

Figura 1. Distribuciones de frecuencias de la severidad de roya del tallo en la población de 99 familias $\mathrm{F}_{6}$ de Apav \#1 $\times$ Kijil en ensayos de campo en Ciudad Obregón, Sonora, ciclos 2015-2016 (RT2016) y 2016-2017 (RT2017). 
Cuadro 3. Número de familias de Apav \# $1 \times$ Kijil positivas y negativas a los marcadores ligados a los genes Sr2, Sr38 y Sr58 y a los genes temporalmente designados SrKj22+, SrKj; 1 y SrKjX- en Ciudad Obregón, Sonora, ciclo 2016-2017.

\begin{tabular}{|c|c|c|c|}
\hline Genes & & Marcador(es) & No. de familias \\
\hline & Sr38 & VENTRIUP-LN2 & 15 \\
\hline & Sr58 & csLV46G22 & 8 \\
\hline & $\mathrm{Sr} 2+\mathrm{Sr} 38$ & Xgwm533 + VENTRIUP-LN2 & 7 \\
\hline & $\operatorname{Sr} 38+\operatorname{Sr} 58$ & VENTRIUP-LN2 + cSLV46G22 & 8 \\
\hline & $\operatorname{Sr} 2+\operatorname{Sr} 58$ & Xgwm533 + csLV46G22 & 9 \\
\hline & $\mathrm{Sr} 2+\mathrm{Sr} 38+\mathrm{Sr} 58$ & Xgwm533 + VENTRIUP-LN2 + csLV46G22 & 7 \\
\hline SrKj22+ & $\operatorname{Sr} 38+\operatorname{Sr} 58$ & VENTRIUP-LN2 + cSLV46G22 & 1 \\
\hline SrKj22+ & Sr2 & Xgwm533 & 1 \\
\hline SrKj22+ & $\operatorname{Sr} 58$ & csLV46G22 & 2 \\
\hline SrKj22+ & $\operatorname{Sr} 2+\operatorname{Sr} 58$ & Xgwm533 + csLV46G22 & 3 \\
\hline SrKj22+ & - & - & 5 \\
\hline SrKj; 1 & Sr2 & Xgwm533 & 8 \\
\hline SrKj; 7 & $\operatorname{Sr58}$ & csLV46G22 & 4 \\
\hline SrKj; 7 & $\operatorname{Sr} 2+\operatorname{Sr} 58$ & Xgwm533 + csLV46G22 & 7 \\
\hline SrKj;1 & - & - & 6 \\
\hline SrKjX- & Sr2 & Xgwm533 & 1 \\
\hline SrKjX- & $\operatorname{Sr} 58$ & csLV46G22 & 1 \\
\hline SrKjX- & $\operatorname{Sr} 2+\operatorname{Sr} 58$ & Xgwm533 + csLV46G22 & 5 \\
\hline- & - & - & 1 \\
\hline
\end{tabular}

que es posible que este gen no se haya observado en otros estudios debido a que el fenotipo que expresa a menudo es confuso. Afortunadamente, el marcador VENTRIUPLN2 es un marcador de diagnóstico efectivo para detectar el segmento del cromosoma 2NS/2AS y en el presente estudio se corroboró la efectividad de tal marcador.

Las líneas resistentes en plántula y positivas a Sr38 presentaron en planta adulta un intervalo de severidad de 0 a $20 \%$ (R-MR), mientras que las familias portadoras de los genes SrKj; 7 , SrKj22+ y SrKjX- expresaron niveles de severidad de 1 a $30 \%$ (R-MR), de 30 a $60 \%$ (MR) y de 1 a $30 \%$ (R-MR), respectivamente. Se observó que todos los genes confirieron un alto nivel de resistencia en planta adulta en la población derivada de Apav \#1 × Kijil, excepto SrKj22+. Estos resultados concuerdan con los de Zhang et al. (2014), quienes reportaron que Sr38 fue el gen más efectivo en planta adulta al presentar un promedio de severidad de $5.2 \%$ en las líneas que portaban sólo este gen, lo cual representó menos de la mitad del valor del segundo gen más efectivo, que fue Sr37, que mostró severidad de $13 \%$. Adicionalmente, Pathan y Park (2007) postularon la combinación de los genes Sr37 + Sr38 en diversos cultivares evaluados, los cuales proporcionaron niveles altos de resistencia en planta adulta, al mostrar niveles de severidad de 20 a $40 \%$, más bajos que aquellos donde el cultivar portaba esos genes de manera individual, lo que sugiere un efecto de interacción entre éstos o la presencia de genes adicionales.

El análisis de segregación mendeliana en planta adulta indicó que la resistencia a roya del tallo en Kijil está conferida por tres genes de resistencia de planta adulta, de los cuales se detectó la presencia de Sr2 y Sr58 con base en el análisis con marcadores moleculares. Las familias positivas a Sr58 mostraron severidades de 30 a 90 \% (MS-S) y sólo una presentó 5 \% (MS) de infección. Estos resultados están relacionados con los obtenidos por García-León et al. (2018), quienes identificaron al gen Sr58 en los genotipos LC-150, Huites M95 y Bonza 63, que mostraron severidades de 0, 10 y $70 \%$, respectivamente, lo que indica que LC-150 y Huites M95 portan genes no identificados que incrementan la efectividad de Sr58. Los mismos autores encontraron la combinación de Sr2 + Sr58 en el genotipo Apav-14, el cual mostró $40 \%$ de severidad y la combinación Sr2 + Sr57 + Sr58 en el progenitor Cacuke mostró el menor nivel de resistencia, correspondiente a $80 \%$ de severidad, a pesar de portar tres genes de efecto 
aditivo. Estos resultados son similares a los obtenidos en el presente estudio, ya que las familias positivas a Sr2 + Sr58 presentaron un intervalo de severidad de 60 a 100 \% (MS-S). Los efectos de Sr2 y Sr58 podrían verse enmascarados por la presencia de algún otro gen, lo que impide que expresen un nivel de resistencia adecuado.

La disminución de la incidencia de roya del tallo a niveles insignificantes en México y en la mayor parte del mundo repercutió en la disminución de la investigación para buscar fuentes de resistencia contra esta enfermedad; sin embargo, se ha seleccionado germoplasma para resistencia a roya del tallo en México para desarrollar epidemias artificiales con la raza RTR de $P$. graminis f. sp. tritici. De acuerdo con los resultados derivados de la presente investigación, Kijil puede ser una fuente potencial de resistencia a roya del tallo para ser usada en programas de mejoramiento, ya que confiere altos niveles de resistencia en plántula y planta adulta.

\section{CONCLUSIONES}

La resistencia en plántula y planta adulta en la población derivada de la cruza Apav \#1 × Kijil está conferida por cuatro genes de raza específica denominados Sr38, SrKj; 7 , SrKj22+ y SrKjX-, mientras que la resistencia en planta adulta está conferida por tres genes de raza no específica, entre ellos los genes Sr2 y Sr58.

\section{AGRADECIMIENTOS}

Los autores agradecen al CIMMYT, Colegio de Postgraduados y CONACYT por el financiamiento y las facilidades concedidas para la realización de este trabajo de investigación.

\section{BIBLIOGRAFÍA}

Bariana H. S. and R. A. McIntosh (1993) Cytogenetic studies in wheat. XV. Location of rust resistance genes in VPM1 and their genetic linkage with other disease resistance genes in chromosome $2 \mathrm{~A}$. Genome 36: 476-482, https://doi.org/10.1139/g93-065

Basnet B. R., S. Singh, E. E. Lopez-Vera, J. Huerta-Espino, S. Bhavani, Y. Jin, M. N. Rouse and R. P. Singh (2015) Molecular mapping and validation of SrND643: a new wheat gene for resistance to the stem rust pathogen Ug99 race group. Phytopathology 105:470-476, https://doi.org/10.1094/PHYTO-01-14-0016-R

Dreisigacker S., D. Sehgal, A. E. Reyes J., B. Luna G., S. Muñoz Z., C. Núñez R., J. Mollins and S. Mall (2016) CIMMYT Wheat Molecular Genetics: Laboratory Protocols and Applications to Wheat Breeding. CIMMYT. México, D.F. 142 p.

Dubin H. J. and J. P. Brennan (2009) Fighting a "Shifty Enemy". The international collaboration to contain wheat rusts. In: Millions Fed. Proven Successes in Agricultural Development. D. J. Spielman and R. Pandya-Lorch (eds.). International Food Policy Research Institute. Washington, D.C. pp:19-24.

García-León E., J. Huerta-Espino, H. E. Villaseñor-Mir, J. S. Sandoval-Islas, S. G. Leyva-Mir, I. Benítez-Riquelme y S. Cruz-Izquierdo (2018) Genética de la resistencia a la roya del tallo en planta adulta en genotipos élite de trigo harinero. Revista Fitotecnia Mexicana 41:385-392.
Helguera M., I. A. Khan, J. Kolmer, D. Lijavetzky, L. Zhong-qi and J. Dubcovsky (2003) PCR assays for the Lr37-Yr Y7-Sr38 cluster of rust resistance genes and their use to develop isogenic hard red spring wheat lines. Crop Science 43:1839-1847, https://doi.org/10.2135/ cropsci2003.1839

Herrera-Foessel S. A., R. P. Singh, M. Lillemo, J. Huerta-Espino, S. Bhavani, S. Singh, C. Lan, V. Calvo-Salazar and E. S. Lagudah (2014) Lr67/ Yr46 confers adult plant resistance to stem rust and powdery mildew in wheat. Theoretical and Applied Genetics 127:781789, https://doi.org/10.1007/s00122-013-2256-9

Huerta-Espino J., H. E. Villaseñor-Mir, E. Espitia-Rangel, E. Solís-Moya and M. van Ginkel (2011) The history of wheat breeding in México. In: The World Wheat Book. A History of Wheat Breeding. Vol. 2. A P. Bonjean, W. J. Angus and M. van Ginkel (eds.). Editions Tec \& Doc. Paris. pp:277-308.

Huerta E. J., R. Torres G., M. F. Rodríguez G., H. E. Villaseñor M., S. G. Leyva M. y E. Solís M. (2012) Resistencia a roya amarilla (Puccinia striiformis f. sp. tritici) en variedades de trigo harinero (Triticum aestivum L.). Revista Mexicana de Ciencias Agrícolas 3:879891, https://doi.org/10.29312/remexca.v3i5.1381

Jin Y., R. P. Singh, R. W. Ward, R. Wanyera, M. Kinyua, P. Njau, T. Fetch, Z. A. Pretorius and A. Yahyaoui (2007) Characterization of seedling infection types and adult plant infection responses of monogenic Sr gene lines to race TTKS of Puccinia graminis f. sp. tritici. Plant Disease 91:10961099, https://doi.org/10.1094/PDIS-91-9-1096

Johnson R. (1981) Durable resistance: definition of genetic control, and attainment in plant breeding. Phytopathology 71:567-568, https://doi.org/10.1094/Phyto-71-567

Kerber E. R. and P. L. Dyck (1973) Inheritance of stem rust resistance transferred from diploid wheat (Triticum monococcum) to tetraploid and hexaploid wheat and chromosome location of the gene involved. Canadian Journal of Genetics and Cytology 15:397-409, https://doi.org/10.1139/g73-050

Lagudah E. S., H. McFadden, R. P. Singh, J. Huerta-Espino, H. S. Bariana and W. Spielmeyer (2006) Molecular genetic characterization of the Lr34/Yr18 slow rusting resistance gene region in wheat. Theoretical and Applied Genetics 114:21-30, https://doi.org/10.1007/s00122-006-0406-z

Lagudah E. S., S. G. Krattinger, S. Herrera-Foessel, R. P. Singh, J. HuertaEspino, W. Spielmeyer, G. Brown-Guedira, L. L. Selter and B. Keller (2009) Gene-specific markers for the wheat gene Lr34/ Yr18/Pm38 which confers resistance to multiple fungal pathogens. Theoretical and Applied Genetics 119:889-898. https://doi.org/10.1007/s00122-009-1097-z

McIntosh R. A., P. L. Dyck and G. J. Green (1977) Inheritance of leaf rust and stem rust resistances in wheat cultivars Agent and Agatha. Australian Journal of Agricultural Research 28:37-45, https://doi.org/10.1071/AR9770037

McIntosh R. A., P. L. Dyck, T. T. The, J. E. Cusick and D. L. Milne (1984) Cytogenetical studies in wheat. XIII: Sr35 - a third gene from Triticum monococcum for resistance to Puccinia graminis tritici. Zeitschrift für Pflazenzüchtung 92:1-14.

McIntosh R. A., C. R. Wellings and R. F. Park (1995) Wheat Rusts: An Atlas of Resistance Genes. CSIRO Publishing. East Melbourne, Australia. 200 p.

McIntosh R. A., J. Dubcovsky, W. J. Rogers, C. Morris and X. C. Xia (2017) Catalogue of gene symbols for wheat: 2017 supplement. Komugi Wheat Genetic Resources Database. Yokohama, Japan. https://shigen.nig.ac.jp/wheat/komugi/genes/macgene/ supplement2017.pdf (September, 2019).

Moore J. W., S. Herrera-Foessel, C. Lan, W. Schnippenkoetter, M. Ayliffe, J. Huerta-Espino, M. Lillemo, L. Viccars, R. Milne, S. Periyannan, X. Kong, W. Spielmeyer, M. Talbot, H. Bariana, J. W. Patrick, P. Dodds, R. Singh, R. and E. Lagudah (2015) A recently evolved hexose transporter variant confers resistance to multiple pathogens in wheat. Nature Genetics 47:1494-1498, https://doi.org/10.1038/ng.3439

Niederhauser J. S., J. Cervantes and L. Servin (1954) Late blight in Mexico and its implications. Phytopathology 44:406-408.

Niu Z., D. L. Klindworth, G. Yu, L. Friesen, S. Chao, Y. Jin, X. Cai, J. B. Ohm, J. B. Rasmussen and S. S. Xu (2014) Development and characterization of wheat lines carrying stem rust resistance gene Sr43 derived from Thinopyrum ponticum. Theoretical and Applied Genetics 
127:969-980, https://doi.org/10.1007/s00122-014-2272-4

Pathan A. K. and R. F. Park (2007) Evaluation of seedling and adult plant resistance to stem rust in European wheat cultivars. Euphytica 155:87-105, https://doi.org/10.1007/s10681-006-9308-z

Peterson R. F., A. B. Campbell and A. E. Hannah (1948) A diagrammatic scale for estimating rust intensity on leaves and stems of cereals. Canadian Journal of Research 26c:496-500, https://doi.org/10.1139/cjr48c-033

Ponce-Molina L. J., J. Huerta-Espino, R. P. Singh, B. R. Basnet, G. Alvarado, M. S. Randhawa, C. X. Lan, V. H. Aguilar-Rincón, R. Lobato-Ortiz and J. J. García-Zavala (2018) Characterization of leaf rust and stripe rust resistance in spring wheat 'Chilero'. Plant Disease 102:421-427, https://doi.org/10.1094/PDIS-11-16-1545-RE

Randhawa M. S., C. Lan, B. R. Basnet, S. Bhavani, J. Huerta-Espino, K. L. Forrest, M. J. Hayden and R. P. Singh (2018a) Interactions among genes Sr2/Yr30, Lr34/Yr78/Sr57 and Lr68 confer enhanced adult plant resistance to rust diseases in common wheat (Triticum aestivum L.) line 'Arula'. Australian Journal of Crop Science 12:1023-1033, http://doi:10.21475/ajcs.18.12.06.PNE1305

Randhawa M. S., R. P. Singh, S. Dreisigacker, S. Bhavani, J. Huerta-Espino, M. N. Rouse, J. Nirmala and M. Sandoval-Sanchez (2018b) Identification and validation of a common stem rust resistance locus in two bi-parental populations. Frontiers in Plant Science 9:1788, https://doi.org/10.3389/fpls.2018.01788

Rodríguez-García M. F., R. I. Rojas-Martínez, J. Huerta-Espino, H. E. VillaseñorMir, E. Zavaleta-Mejía, J. S. Sandoval-Islas y J. F. Crossa-Hiriart (2019) Genética de la resistencia a roya amarilla causada por Puccinia striiformis f. sp. tritici W. en tres genotipos de trigo (Triticum aestivum L.). Revista Fitotecnia Mexicana 42:31-38.

Roelfs A. P., R. P. Singh and E. E. Saari (1992) Rust Diseases of Wheat. Concepts and Methods of Disease Management. CIMMYT. Mexico, D. F. 81 p.

Singh R. P. (1991) Pathogenicity variations of Puccinia recondita $f$. sp. tritici and $P$. graminis f. sp. tritici in wheat-growing areas of Mexico during 1988 and 1989. Plant Disease 75:790-794, https://doi.org/10.1094/PD-75-0790

Singh R. P. and S. Rajaram (1992) Genetics of adult-plant resistance of leaf rust in 'Frontana' and three CIMMYT wheats. Genome 35:24-31, https://doi.org/10.1139/g92-004

Singh R. P., J. Huerta-Espino and S. Rajaram (2000) Achieving nearimmunity to leaf and stripe rusts in wheat by combining slow rusting resistance genes. Acta Phytopathologica et Entomologica Hungarica 35:133-139.

Singh R. P., D. P. Hodson, Y. Jin, J. Huerta-Espino, M. G. Kinyua, R. Wanyera, P. Njau and R. W. Ward (2006) Current status, likely migration and strategies to mitigate the threat to wheat production from race Ug99 (TTKS) of stem rust pathogen. CAB Reviews: Perspectives in Agriculture, Veterinary Science, Nutrition and Natural Resources 1:1-13. https://doi.org/10.1079/pavsnnr20061054

Singh R. P., D. P. Hodson, J. Huerta-Espino, Y. Jin, P. Njau, R. Wanyera, S A. Herrera-Foessel and R. W. Ward (2008) Will stem rust destroy the world's wheat crop? Advances in Agronomy 98:271-309, https://doi.org/10.1016/S0065-2113(08)00205-8

Singh R. P., D. P. Hodson, J. Huerta-Espino, Y. Jin, S. Bhavani, P. Njau, S. HerreraFoessel, P. K. Singh, S. Singh and V. Govindan (2011a) The emergence of $\mathrm{Ug} 99$ races of the stem rust fungus is a threat to world wheat production. Annual Review of Phytopathology 49:465-481, https://doi.org/10.1146/annurev-phyto-072910-095423

Singh R. P., J. Huerta-Espino, S. Bhavani, S. A. Herrera-Foessel, D. Singh, P. K. Singh, G. Velu, R. E. Mason, Y. Jin, P. Njau and J. Crossa (2011b) Race non-specific resistance to rust diseases in CIMMYT spring wheats. Euphytica 179:175186, https://doi.org/10.1007/s10681-010-0322-9

Spielmeyer W., P. J. Sharp and E. S. Lagudah (2003) Identification and validation of markers linked to broad-spectrum stem rust resistance gene Sr2 in wheat (Triticum aestivum L.). Crop Science 43:333-336, https://doi.org/10.2135/cropsci2003.3330

The T. T. (1973) Chromosome location of genes conditioning stem rust resistance transferred from diploid to hexaploid wheat. Nature New Biology 241:256, https://doi.org/10.1038/newbio241256a0

Turner M. K., Y. Jin, M. N. Rouse and J. A. Anderson (2016) Stem rust resistance in 'Jagger' winter wheat. Crop Science 56:17191725, https://doi.org/10.2135/cropsci2015.11.0683

Zárate-Castrejón J. L., C. L. Aguirre-Mancilla, E. Solís-Moya, A. P. RodríguezVera, J. C. Raya-Pérez, J. G. Ramírez-Pimentel y V. Montero-Tavera (2018) Genes candidatos de respuesta a roya de la hoja de trigo identificados por perfiles de expresión. Revista Fitotecnia Mexicana 41:527-535

Zhang D., R. L. Bowden, J. Yu, B. F. Carver and G. Bai (2014) Association analysis of stem rust resistance in U.S. winter wheat. PLOS ONE 9:e103747, https://doi.org/10.1371/journal.pone.0103747 